\section{MEDICAL CERTIFICATES.}

CoNsIDERABLE interest attaches to the investigation which the Hospital Saturday Fund has just completed into the provision of medical certificates at the various London hospitals. In view of the complications that may arise from accident or disease should the victim claim compensation under the Workmen's Compensation Act, the issue of such certificates is a matter of great importance. Witin regard to certificates issued to workmen who may use such documents in order to obtain compensation, the official organ of the Saturday Fund states that the recipient ought to be made to pay for them. It seems that all institutions issue such certificates, stating the nature of the disease or injury, and whether or not the patient is able to follow his usual employment. In no case is a charge made unless expressions of professional opinion, other than statements of facts, are required. Where, however, a certificate is required by the employers, by firms, or by solicitors, the usual fee of a guinea is charged. Some hospitals provide facilities for medical men, acting on behalf of insurance companies or employers, to examine patients in the wards, such examination being conducted in the presence of a house officer. The usual custom is for the superintendent to regulate the fee charged by residents for the issue of certificates wherein expressions of professional opinion are involved. Some months ago a case in connection with such custom arose at the Johannesburg Hospital, where the resident medical officer refused to give a certificate unless the usual guinea was paid by the solicitor. Complaint was made to the House Committee, which, we believe, upheld the view of the resident.

\section{SCHOOL CERTIFICATES.}

THE matter of school certificates is an important one in view of the fact that an increasing number of school children attend the London hospitals. Since the London County Council began to subsidise certain hospitals conditionally upon the latter treating certain classes of physically defective children, fresh difficulties have arisen in connection with the matter of granting exemption certificates. Some physicians, we know, refu'se to grant certificates on principle. 'They allege, with perfect justice, that the out-patient card is sufficient proof that the child is attending hospital and ought not to go to school, and we have even heard physicians who advised mothers to " have the inspector up for assault ", if. he dared force the attendance of the child. This is a perfectly logical position, but it is one the justice of which ordinary inspectors fail to see. They insist upon their certificates, and endless trouble and vexation arise not only to the parents, but sometimes also to the surgeon or physician, unless a proper exempting order is granted. It is high time that some concerted action be taken in the matter. The various hospitals ought to discuss the whole matter, as the Saturday Fund suggests, with the large Funds, and acquire all information that is available. With the opinion that it is not fair that insurance companies and employers, whose interests are always protected, should not pay a fair price for " information required " every hospital worker will cordially agree. Where a poor workingman demands a certificate it should be left to the discretion of the officer in charge of the department to issue it or not, provided always that no refusal is permitted in cases where the certificate is required by a patient too poor to pay the usual fee.

\section{THE DRUG MARKET.}

THE improvement in the demand for drugs which was noticed last week is maintained, and although only slight is much appreciated in the drug market. Prices on the whole are well maintained. At present there are no signs indicating a probable reduction in the price of ipecacuanha, but few buyers would be willing to pay the high prices asked unless they were in immediate need of the drug. In spite of the small demand, cod-liver oil is slightly dearer again. Santonin is $2 \mathrm{~s}$. 3d. per $1 \mathrm{~b}$. higher, and it is not improbable that the syndicate which appears to have regained control of this article will advance the price again in due course. Not only has the decline in the price of Buchu leaves ceased, but prices have moved in the other direction and are about $3 \mathrm{~d}$. per lb. higher; buyers of Buchu leaves should act with caution. Cubebs are fetching very high prices owing to extreme scarcity; oil of cubebs is also dearer in consequence. The advance in the price of saffron continues. At the recent public sale of drugs in Mincing Lane, rhubarb was slightly cheaper. Makers of cocaine are not willing to sell at the reduced price announced last week, and it is not improbable that the price will be advanced.

\section{INSTITUTIONAL LETTER-BOX.}

\section{THE RATING OF VOLUNTARY HOSPITALS. To the Editor of The Hospital.}

Sin,-I trust you will not think I am attaching too great importance to my opinions if $\mathrm{I}$ ask you to make a correction in the statement of views on the subject of the rating of hospitals which you attributed to me in the last number of The Hospital. You say "Mr. Johnson, of Great Ormond Street (is) decidedly against the total exemption of hospitals from local taxation." This is only half the truth. It is true that I am not in favour of the hospitals being exempted from the payment of rates at the cost of the particular borough in which they are situated, but I am in favour of the hospitals being totally exempted from the burden of local taxation at the cost of the areas from which the hospitals' patients are drawn. This, in my opinion, can best be effected by allowing the hospitals to pay rates to the local authorities and then refunding them to the hospitals from the Metropolitan Pocr Fund, as was suggested at the Conference on Rating held under the auspices of the London County Council in 1907.

I am, dear sir, yours faithfully,

Stewart Johnson.

April 11. Secretary.

Mr. James Paterson, of Midlothian, has left $£ 40,000$ for the foundation and maintenance of a nursing home in the Bridgeton district of Glasgow, and $£ 5,000$ to each of four Glasgow institutions, and $£ 20,000$ for such charitable purposes as the trustees may select. 